\title{
To Study and Compare the Effects of Aspirin and Nigella Sativa on Coagulation Profile in Albino Rats for Six Weeks
}

\author{
A MUNIR* M TAYYIB* $\mathrm{T}$ TASNEEM* MFAROOQ* MASHRAF** A DITTA* N A CHAUDHRY* A RASHID*** \\ *Postgraduate Medical Institute. Lahore. \\ **Pharmacy Department. Islamia University, Bahawalpur. \\ ***Department of Medicine. Mayo Hospital, Lahore \\ Correspondence to Dr. Akhtar Munir
}

\begin{abstract}
Ninety albino rats were selected and were divided into six groups on the basis of different diets given. Control group (I) was fed on synthetic diet and experimental groups (IIA, IIB, IIC, IID and IIE) were fed on $1 \mathrm{mg}$ aspirin, $15 \mathrm{mg}, 30 \mathrm{mg}, 45 \mathrm{mg}$ Nigella Sativa per kg body weight respectively while IIE was given $30 \mathrm{mg}$ NS and $1 \mathrm{mg}$ aspirin/kg body wt. Blood samples were collected by heart puncture and different tests were done. Bleeding time was shortened significantly in groups taking N.S. when compared with control. BT was prolonged in groups taking aspirin only. APTT was reduced significantly in groups taking different concentration of NS when compared with control. Percentage of clot retraction was weak significantly in groups taking aspirin only when comparing with other groups.
\end{abstract}

Key words: Aspirin, Nigella Sativa

Nigella Sativa seeds are extensively used as medicine. The Hakeems prescribe it as diuretic. carminative and anthelmintic. It also considers to increase the menstrual blood flow and secretion of milk. The seed gives relief when bruised with vinegar and applied on pityriasis. Leucoderma. wring worm. eczema and alopecia. EI-Dakhakhany $(1983)^{1}$ isolated a crystalline active principle from the essential oil of Nigella Sativa which later proved to be the dimmer of thymoquinone; he found that the carboxyl fraction isolated from the volatile oil was polythymoquinone and it possessed lower toxicity than thymoquinone itself.

Nigella Sativa seeds have been shown to posses significant anthelmintic effect in young children ${ }^{2}$. Salomi et al $(1992)^{3}$ reported that it had cytotoxic effect by administering in two patients with malignant ulcer on the face. It produces significant shortening of clotting, bleeding. thrombin, prothrombin and partial thromboplastin times in rats ${ }^{4,5.8}$. Nigella Sativa has also been administered for the treatment of jaundice 6 . Seeds of Nigella sativa are given with butter and milk to cure obstinate hiccup. Seeds are employed as a purgative. They are also useful in indigestion, loss of appetite, fever, diarrhea, and puerperal disease etc ${ }^{7}$. NS produced significant shortening in kaolin cephalin clotting time. Ether extracts and fatty extract produced a significant shortening in bleeding time $e^{4}$.

Petroleum ether extracts produced significant shortening in the whole blood clotting times and activated partial thromboplastin time. No significant effect was shown on the prothrombin time and thrombin times. The fatty extract and petroleum ether inhibited the fibrinolytic activity in vivo and in vitro. The mechanism of this effect is not known but it may be due to an inhibitory effect on the activation of plasminogen or inhibiting the plasmin activity ${ }^{10}$.

\section{Subjects and methods}

Ninety male albino rats were divided into different groups on the basis of diet (Tablel). Blood sampling was done at $6^{\text {th }}$ week. Routine haematological investigations ( $\mathrm{Hb}, \mathrm{TLC}, \mathrm{DLC}$, platelets) and special investigation (PT. APTT, BT, clot retraction and fibrinogen) were performed.
Table I Groups of animals based on diet

\begin{tabular}{|c|c|c|}
\hline Groups & $\mathrm{n}=$ & Type of diet/rat twice a day \\
\hline I (Control) & 15 & 10gms (synthetic diet) \\
\hline $\begin{array}{l}\text { Experimental } \\
\text { group (II) }\end{array}$ & 75 & \\
\hline IIA & 15 & $0.2 \mathrm{mg}$ aspirin \& $10 \mathrm{~g}$ synthetic diet \\
\hline IIB & 15 & $\begin{array}{l}3.0 \mathrm{mg} \text { Nigella Sativa \& } 10 \mathrm{~g} \\
\text { synthetic diet }\end{array}$ \\
\hline IIC & 15 & $\begin{array}{l}6.0 \mathrm{mg} \text { Nigella Sativa \& } 10 \mathrm{~g} \\
\text { synthetic diet }\end{array}$ \\
\hline IID & 15 & $\begin{array}{l}9.0 \mathrm{mg} \text { Nigella Sativa \& } 10 \mathrm{~g} \\
\text { synthetic diet }\end{array}$ \\
\hline IIE & 15 & $\begin{array}{l}0.2 \mathrm{mg} \text { aspirin }+3 \mathrm{mg} \text { Nigella sativa } \\
\& 10 \mathrm{~g} \text { synthetic diet }\end{array}$ \\
\hline
\end{tabular}

Results

The results of different groups at $6^{\text {th }}$ week (Tables $2 \& 3$ ).

Table 2 Routine haematological investigations in experimental and control groups at $6^{\text {th }}$ week

\begin{tabular}{llll}
\hline Groups & Hb $(\mathrm{g} / \mathrm{dl})$ & TLC $\left(10^{9} / \mathrm{L}\right)$ & Platelets $\left(10^{9} / \mathrm{L}\right)$ \\
\hline I & $11.8 \pm 0.9$ & $6.2 \pm 0.5$ & $989 \pm 9.54$ \\
& $(12-12.8)$ & $(5.8-6.4)$ & $(976-963)$ \\
IIA & $12.2 \pm 0.44$ & $5.5 \pm 0.41$ & $966 \pm 49.1$ \\
& $(11.6-12.8)$ & $(5.0-6.0)$ & $(978-100)$ \\
IIB & $12.6 \pm 0.75$ & $6.3 \pm 0.33$ & $965 \pm 43.8$ \\
& $(11.8-13.8)$ & $(6.0-6.8)$ & $(890-993)$ \\
IIC & $12.7 \pm 0.2$ & $5.8 \pm 0.5$ & $974 \pm 6.4$ \\
& $(12.4-13.0)$ & $(5.0-6.2)$ & $(965-928)$ \\
IID & $12.7 \pm 0.8$ & $6.2 \pm 0.3$ & $982 \pm 12.0$ \\
& $(12-14.0)$ & $(5.8-6.4)$ & $(965-990)$ \\
IIE & $12.9 \pm 0.4$ & $6.0 \pm 0.2$ & $978 \pm 10.0$ \\
& $(12.4-13.4)$ & $(5.8-6.2)$ & $(965-992)$ \\
Statistical & Analysis & & NS \\
I/IIA & NS & S & NS \\
I/IIB & $\mathrm{S}$ & NS & S \\
I/IIC & $\mathrm{S}$ & NS & NS \\
I/IID & NS & NS & NS \\
I/IIE & $\mathrm{S}$ & NS &
\end{tabular}


Table 3 Specific haematological investigations in experimental and control groups at $6^{\text {th }}$ week

\begin{tabular}{llllll}
\hline Groups & Clot Retraction & BT (Minute) & PT (Second) & APTT (Second) & Fibrinogen (mg/dl) \\
\hline I & $54 \pm 1.41(50-54)$ & $3.5 \pm 0.48(3.2-4.3)$ & $12.2 \pm 0.84(11-13)$ & $34.2 \pm 1.48(32-36)$ & $244 \pm 76.6(175-375)$ \\
IIA & $51.1 \pm 1.7(50-56)$ & $6.4 \pm 0.65(5.4-6.8)$ & $12.0 \pm 1.0(11-13)$ & $35 \pm 3.0(32-40)$ & $234 \pm 10.2(160-180)$ \\
IIB & $55.0 \pm 11.8(50-57)$ & $2.9 \pm 0.36(2.6-3.4)$ & $11.8 \pm 0.8(11-13)$ & $29.2 \pm 1.92(28-32)$ & $243-77.7(117-375)$ \\
IIC & $56.6 \pm 4.99(52-62)$ & $2.6 \pm 0.3(2.2-3.0)$ & $12.0 \pm 1.0(11-13)$ & $30.0 \pm 1.4(28-32)$ & $231 \pm 27.7(175-230)$ \\
IID & $57 \pm 4.2(52-62)$ & $2.7 \pm 0.3(2.2-3.0)$ & $12.2 \pm 1.3(11-13)$ & $29.6 \pm 1.8(27-32)$ & $239 \pm 22.2(155-210)$ \\
IIE & $56.4 \pm 1.7(54-58)$ & $3.6 \pm 0.5(3.0-4.2)$ & $12.6 \pm 1.1(11-14)$ & $33.8 \pm 3.7(30-40)$ & $217 \pm 73.6(160-340)$ \\
Statistical & Analysi & & & & NS \\
I/IA & S & HS & NS & HS & NS \\
IIIB & NS & S & NS & HS & NS \\
I/IIC & S & HS & NS & HS & NS \\
I/IID & S & S & NS & NS & NS \\
I/IIE & HS & NS & & & \\
\hline
\end{tabular}

\section{Discussion}

Hb: Mean $\mathrm{Hb}$ conc. of groups IIB, IIC \& IIE in $6^{\text {th }}$ week was raised significantly $(\mathrm{p}<0.05)$ when comparing with control group. Raised $\mathrm{Hb}$ value of albino rats on different conc. of Nigella sativa diet with and without aspirin supplement can be attributed to some un-known stimulatory effect of Nigella sativa (NS) on haematopoetic system/or may be due to balanced diet provided during study.

TLC: TLC in group taking aspirin only (IIA) was reduced significantly while other groups taking NS showed nonsignificant result when comparing with control group at $6^{\text {th }}$ week.

Platelets: The mean \pm SD platelets values of control groups were found to be non-significant at $6^{\text {th }}$ week when compared with experimental groups.

Clot retraction: At $6^{\text {th }}$ week when comparing control group with group taking aspirin only (IIA), there was decreased percentage of clot retraction and the difference was significant $(p<0.05)$ statistically. While comparison of groups IIA vs IIB, IIA vs IIC, IIA vs IID and IIA vs IIE showed increase percentage of clot retraction in groups taking different conc. of NS and the difference was significant $(p<0.05)$ statistically.

Bleeding Time: The mean \pm SD values of BT in experimental groups IIB, IIC \& IID were shortened significantly $(\mathrm{p}<0.05)$ when comparing with control group (I) at $6^{\text {th }}$ week while prolonged significantly $(p<0.05)$ in group IIA at $6^{\text {th }}$ week. This shortened BT in different groups may be due to the effects of Nigella sativa which may result in increase in functional property of platelets. Group IIA showed prolonged BT which is due to antiplatelet effect of aspirin present in this group Such results are also seen in the study of Tocantins $(1936)^{8}$ who also observed shortening of BT by using fatty and petroleum ether extracts of Nigella sativa.

Prothrombin Time: The mean $\pm \mathrm{SD}$ values of $\mathrm{PT}$ in experimental groups IIA, IIB, IIC IID \& IIE were comparable with that of control groups. When comparing experimental groups to one another, non-significant difference observed.

Activated Partial Thromboplastin Time: The mean \pm SD values of APTT in experimental groups taking NS only was significantly $(p<0.05)$ decreased when comparing with control group (IA) at $6^{\text {th }}$ week but comparable in groups taking aspirin at $6^{\text {th }}$ week. This decreased APTT in groups containing Nigella sativa may be due to effect of NS on factors involved in the intrinsic coagulation pathway. Such results are in conformity with the study of Owen et al $(1975)^{9} \&$ Ghoneum et al $(1982)^{4}$ who also observed similar changes.

Fibrinogen Level: The mean \pm SD values of fibrinogen in experimental groups IIA, IIB, IIC IID and IIE was comparable when comparing with control group (I) at $6^{\text {th }}$ week. The comparison between different experimental groups to each other also showed non-significant difference statistically.

\section{References}

1. El-Dakhakhany M. Some pharmacological properties of some constituents of Nigella sativa seeds. Planta Med 1983: 426-28.

2. Akhtar MS. Riffat S. Field trial of saussurea lappa roots against nematodes and Nigella sativa seed against cestodes in children JPMA 1991: 41: 185-87.

3. Salomi MJ. Nair SC, Varghese CD. Antitumour principles from Nigella sativa seeds. Cancer Latter 1992: 63(1):4-46.

4. Ghoneim MT. El-Gindy. R. Possible effects of some extracts of Nigella sativa seeds on blood coagulation system and fibrinolytic activity. Proceeding of the $2^{\text {nd }}$ International Conference of Islamic Medicine, Kuwaits. 1982: 528-35.

5. Blatter E. Caius JF, Mhaskar KS. Indian Medicinal plants $2^{\text {nd }}$ Ed. Allahabad. India Lalit Mohan Basu. 1984: $11-2$.

6. Veed G. Ragnstrom J. Nilson J. Role of lipids and antioxidative factors for development of atherosclerosis. Am J Cardiol 1993; 71:15B-19B.

7. Bavaprakash N. Ayurvedic Medicine. Lahore: Idara Matbuaat Sulemani 1992: 524-27.

8. Tocantins LM. Functions of Nigella Sativa seeds Am J Clin Pathol 1936:6.

9. Owen $\mathrm{CH}$, Walter Bowie EJ, Thompson JH. Haemostasis and Blood Coagulation. In: The diagnosis of bleeding disorders. $2^{\text {nd }}$ Ed. Little Brown and Co.. Boston 1975. III.

10. Hardy RH. Nigella Sativa seeds. Br Med J 1974: 224.

11. Ghaznavi K. Tibbe-Nabvi, Lahore: Al-Faisal Ghaznavi street urdu Bazar 1997: 25-35.

12. Rampuri Allama Hakim Molvi Najmul Ghani. Tibbi Encyclopaedia 1993: 388-391. 